\title{
Burden, Emotional Distress and Quality of Life among Informal Caregivers of Lung Cancer Patients: An Exploratory Study
} Dol:

10.1111/ecc. 12691

\section{Document Version}

Accepted author manuscript

Link to publication record in Manchester Research Explorer

\section{Citation for published version (APA):}

Tan, J-Y., Molassiotis, A., Lloyd-Williams, M., \& Yorke, J. (2017). Burden, Emotional Distress and Quality of Life among Informal Caregivers of Lung Cancer Patients: An Exploratory Study. European Journal of Cancer Care. https://doi.org/10.1111/ecc.12691

\section{Published in:}

European Journal of Cancer Care

\section{Citing this paper}

Please note that where the full-text provided on Manchester Research Explorer is the Author Accepted Manuscript or Proof version this may differ from the final Published version. If citing, it is advised that you check and use the publisher's definitive version.

\section{General rights}

Copyright and moral rights for the publications made accessible in the Research Explorer are retained by the authors and/or other copyright owners and it is a condition of accessing publications that users recognise and abide by the legal requirements associated with these rights.

\section{Takedown policy}

If you believe that this document breaches copyright please refer to the University of Manchester's Takedown Procedures [http://man.ac.uk/04Y6Bo] or contact uml.scholarlycommunications@manchester.ac.uk providing relevant details, so we can investigate your claim.

\section{OPEN ACCESS}




\section{Burden, Emotional Distress and Quality of Life among Informal Caregivers of Lung Cancer Patients: An Exploratory Study}

Jing-Yu Tan RN, PhD Candidate

School of Nursing, The Hong Kong Polytechnic University, Hung Hom, Kowloon, Hong Kong Division of Nursing, Midwifery and Social Work, University of Manchester, Manchester, UK

Alex Molassiotis RN, PhD, Chair Professor of Nursing

School of Nursing, The Hong Kong Polytechnic University, Hung Hom, Kowloon, Hong Kong Division of Nursing, Midwifery and Social Work, University of Manchester, Manchester, UK

Mari Lloyd-Williams MD, FRCP, FRCGP, Professor and Honorary Consultant in Palliative Medicine Institute of Psychology Health and Society, University of Liverpool, Liverpool, UK

Janelle Yorke RN, PhD, Professor of Cancer Nursing

Division of Nursing, Midwifery and Social Work, University of Manchester, Manchester, UK The Christie NHS Foundation Trust, Manchester, UK

Corresponding Author:

Professor Janelle Yorke

Professor of Cancer Nursing

Division of Nursing, Midwifery and Social Work

University of Manchester

Room 5.320, Jean McFarlane Building

Oxford Road

Manchester M139PL

janelle.yorke@manchester.ac.uk

(+44) 1613067780 


\title{
Burden, Emotional Distress and Quality of Life among Informal Caregivers of Lung Cancer Patients: An Exploratory Study
}

\begin{abstract}
This study was conducted to explore the interrelationships among caregiver burden, emotional status and quality of life (QoL) in caregivers of lung cancer patients, and to identify whether caregiver burden and health status are associated with patient emotional status and QoL. Forty-three dyads of lung cancer patients and their caregivers were included for analysis. Caregiver-reported outcomes were measured by Caregiver Burden Scale (CBS), Caregivers Quality of Life Index-Cancer (CQOLC) and Hospital Anxiety and Depression Scale (HADS), while patient-reported outcomes were collected by HADS and Lung Cancer Symptom Scale (LCSS). The majority of the CBS and CQOLC scores were significantly higher in anxious and depressed caregivers than non-anxious and non-depressed caregivers $(P<0.01$ or 0.05$)$. Caregivers of depressed patients experienced significantly greater emotional distress than those of non-depressed patients $(P<0.01)$. Significantly positive associations were identified among most of the CBS, CQOLC and caregiver HADS scores. Patient LCSS scores were positively correlated with the CBS and caregiver HADS scores, and patient HADS scores were also positively related to caregiver HADS scores. The close interrelationships between caregiver and patient health outcomes provide evidence that lung cancer patients and their caregivers should be viewed as a unit in future supportive service models.
\end{abstract}

\section{KEYWORDS}

Informal caregiver; Lung cancer; Caregiver burden; Anxiety; Depression; Quality of Life 


\section{INTRODUCTION}

Lung cancer is one of the most frequent cancer diagnoses and one of the leading causes of cancer death around the world, with about 1.8 million new cases and 1.6 million deaths identified in 2012 (Torre et al. 2015). Symptom burden in lung cancer places considerable physical and psychological distress on patients' well-being as both the disease-specific and treatment-induced symptoms could result in a series of impairments on patients' emotional status, social functions and quality of life (QoL) (Ellis 2012; Fox \& Lyon 2006). Compared to other cancer diagnoses, symptom distress in lung cancer patients has been identified to be the most significant (Ellis 2012), which often contributes to heavy burden on their primary caregivers. Taking into account the current trend of shortened period of the length of stay in hospital, duties for patient care have been shifted from the professional caregivers to patients' family members (Kurtz et al. 1994; Stenberg et al. 2010). The primary caregivers of cancer patients are often their spouses, partners, close relatives or friends, which are usually described as "informal caregivers", a term used to distinguish from the care provided by healthcare professionals (in this paper, "informal caregiver" is referred to as "caregiver") (Beesley 2006; Perz et al. 2011). Caring for lung cancer patients could be a long journey, as cancer survival rates have been gradually increasing with advances in anticancer therapies and supportive care (Weitzner et al. 2000). Caregivers often face the challenge of providing long-term care and physical, psychosocial and financial burden induced by daily care of the patients.

Caregiver burden is defined as "the emotional, social, and financial stress that illnesses impose on caregivers" (Chessick et al. 2007, p483). Caregiver burden of caring for lung cancer patients (as well as patients with other types of cancer) is considerable and increases over time, as caregivers engage in a wide range of care activities including direct personal care, home-based treatments, patient emotional and spiritual support, and household duties (Girgis et al. 2013; Girgis \& Lambert 2009; Given et al. 2004). In addition, unsatisfactory symptom management of the patients often leads to frequent hospitalisations (Ellis 2012) and emergency department visits, which is energyand time- consuming for the caregivers. Unfortunately, there is seldom support for caregivers (Ellis 2012; Plant 2011), and their health conditions are often overlooked by healthcare professionals.

A systematic review summarised family caregiver health problems associated with caring for different cancer patients including lung, breast and gastrointestinal, etc. (Stenberg et al. 2010). Caregiver burden was found to be significant and mostly associated with direct and indirect care responsibilities for the cancer patients, and the most commonly identified physical problems were sleep problems, fatigue, pain, and physical weakness (Stenberg et al. 2010). Anxiety and depression were the commonly reported emotional problems among caregivers of cancer patients, with the incidence ranging from $34.5 \%$ to $39.7 \%$, and $10.3 \%$ to $38.9 \%$, respectively, and sometimes even higher than the patients' incidence rates (Braun et al. 2007; Clavarino et al. 2002; Grunfeld et al. 2004; Janda et al. 2008).

Psychosocial stress highlighted in the definition of caregiver burden (Chessick et al. 2007) reveals a possible relationship between caregiver burden and QoL, as QoL is also a multi-dimensional concept 
which include both physical and psychosocial components (Kim \& Given 2008). Studies have emphasised that burden of caring for cancer patients and the negative experiences associated with caregiving activities might affect caregivers' QoL (Kim \& Given 2008; Milbury et al. 2013), and subsequently impede patients' psychological well-being (Milbury et al. 2013). Psychological distress (especially depression) in caregivers, which has been proved to be a strong predictor of "potentially harmful caregiver behaviour" (Williamson \& Shaffer 2001, p222), is also believed to be related to caregiver burden of caring for patients with chronic conditions (Hooley et al. 2005). Taking into account the considerable impact of cancer on both patients and their caregivers (Ellis 2012; Stenberg et al. 2010), it is possible that there would be close associations of caregiver burden with psychological distress (Milbury et al. 2013) and QoL of both cancer patients and their caregivers.

Several studies have been conducted so far to explore the associations of caregiving burden with other caregiver variables among caregivers of cancer patients. Caregiver burden in spousal/family caregivers was found to be associated with their own psychological distress (Fujinami et al. 2015; Kim et al. 2005; Milbury et al. 2013). Greater caregiver burden was also found to be related to poorer QoL among family caregiver (Fujinami et al. 2015; Rha et al. 2015). Linkage between depressive symptoms and QoL among family caregivers of cancer patients has also been examined in a recent study and caregivers' depressed mood was shown to be closely associated with their own concurrent QoL (Kim et al. 2015). However, most of the studies on caregivers of cancer patients have only focused on the depressive aspect of emotional problems, and the QoL measurements used in those studies were mostly generic instruments but not specific for caregivers of cancer patients. Studies that investigate the interrelationships of caregiver burden with both emotional distress and QoL among caregivers of cancer patients have been scanty.

Relationships between caregiver and cancer patient outcomes have been explored in several studies. Caregiver burden in caregivers of lung cancer patients showed significant association with patients' psychological functions (Milbury et al. 2013). A close relationship between cancer patients and their family caregivers in terms of QoL and depressive symptoms has also been revealed in a most recent study (Litzelman et al. 2016). Association in QoL between cancer patients and their caregivers is often overlooked in practice and related studies remain sparse and the findings are sometimes conflicting. Three recent studies have demonstrated a positive relationship between caregiver QoL and cancer patient QoL (Litzelman et al., 2016; Shahi et al. 2014; Wadhwa et al. 2013), while another two studies on spousal/family caregivers of cancer patients reported no significant relationship in QoL between family members and patients (Chen et al. 2004; Sarna et al. 2006).

A comprehensive understanding of the interrelationships among caregiver burden, emotional status and QoL in caregivers of cancer patients is essential for developing tailored supportive services. Given the close linkage between caregivers and cancer patients, potential associations of caregiver burden and health status with patient outcomes are also worthy of further exploration to retrieve implications for a future targeted strategy to improve both patients' and caregivers' well-being. To our knowledge there have been few studies in lung cancer that specifically focus on the interrelationships of caregiver burden with both caregiver emotional stress (anxiety and depression) 
and QoL, and the current evidence relating to associations between caregiver and cancer patient health outcomes has been conflicting. To advance existing literature on the understanding of caregiver burden of caring for lung cancer patients, this study was conducted to explore the interrelationships among burden, emotional status and QoL in caregivers of lung cancer patients, and to investigate the associations between caregiver and patient health outcomes.

\section{METHODS AND MATERIALS}

\section{Study design}

This exploratory study was a cross-sectional design using baseline data from a recent feasibility randomised controlled trial (RCT) on lung cancer (ISRCTN13173844) (Yorke et al. 2016). Ethical approval was received (NHS reference number: 12/NW/0090) and local site approvals were attained from participating hospitals. Written informed consent was also obtained from all caregivers and patients who agreed to participate in the study.

\section{Overview of the feasibility randomised controlled trial}

The RCT was conducted in 11 NHS hospitals in the north of England (Yorke et al. 2016). It aimed to assist the self-management on the respiratory distress symptom cluster (breathlessness-coughfatigue) (Molassiotis et al. 2011) in patients with lung cancer. Eligible patients were those who had a confirmed diagnosis of primary lung cancer with at least two symptoms experienced from the symptom cluster (Yorke et al. 2016). There were 107 patients and 50 caregivers included in the feasibility trial. Caregivers were nominated by the patients who were then provided with study information and a separate consent form for completion. All patient and caregiver outcome measures were self-completed. Seven caregivers did not complete the baseline assessment and were removed from this analysis. Therefore, 43 caregivers together with their respective lung cancer patients (43 dyads) were included in this study for analysis.

\section{Caregiver and patient- reported outcomes}

Outcome measures which were most relevant to this exploratory study were retrieved. Related caregiver and patient-reported instruments are described as follows.

\section{- Demographic questionnaires}

Caregiver demographic data including age, gender, relationship with patient, and employment status were collected. For lung cancer patients, demographic data such as age, gender, employment status, ECOG/WHO performance status and treatment conditions were recorded.

\section{- Caregiver Burden Scale (CBS) (caregiver completed)}

The CBS is a self-reported 22-item instrument designed to measure caregiver burden (Elmståhl et al. 1996). Five domains are incorporated into the scale including: general strain (8-item), isolation (3item), disappointment (5-item), emotional involvement (3-item) and environment (3-item) (Andrén \& Elmståhl 2005; 2008; Elmståhl et al. 1996). Each item is rated on a 4-point Likert scale from 1 (not at all) to 4 (often), and the mean of all 22 items contributes to the total CBS score (Andrén \& Elmståhl 2005; 2008). Higher scores represent worse outcomes (Andrén \& Elmståhl 2005). Satisfactory reliability of the CBS has been documented, with the kappa values ranging from 0.69 to 1.00 for the total and domain scores (Elmståhl et al. 1996).

\section{- Caregivers Quality of Life Index-Cancer (CQOLC) (caregiver completed)}


The CQOLC is a 35-item self-reported instrument, and each item is scored from 0 (not at all) to 4 (very much) (Lafaye et al. 2013; Weitzner et al. 1999). Four conceptual dimensions of caregiver QoL are captured by the CQOLC with four domains: burden (10-item), disruptiveness (7-item), positive adaption (7-item) and financial concern (3-item) (Lafaye et al. 2013). In addition, there are eight single items not part of any domain (Lafaye et al. 2013). The score for each domain is achieved by summing up the related domain item scores, and the CQOLC total score is calculated by summing up all the 35 items scores (Carter, 2006; Lafaye et al. 2013). Higher scores reflect worse QoL (Carter, 2006; Ozer et al. 2009). Reliability of the CQOLC is good, with the internal consistency coefficient being 0.91 and test-retest correlation coefficient being 0.95 (Weitzner et al. 1999). Convergent and divergent validity were also proved to be adequate when tested against other similar/dissimilar instruments (Weitzner et al. 1999).

\section{- Hospital Anxiety and Depression Scale (HADS) (caregiver and patient completed)}

The HADS is a well-known self-administered tool for measuring the levels of anxiety and depression, with adequate psychometric properties documented in the literature (Zigmond \& Snaith 1983). It consists of 14 items (each item score ranges from 0 to 3 ), with seven items contributing to the anxiety subscale (HADS-A, 0 to 21) and another seven contributing to the depression subscale (HADS-D, 0 to 21) (Snaith 2003). Higher scores indicate more severe emotional distress. Correlations between HADS-A and HADS-D ranged from 0.40 to 0.74 (Bjelland et al. 2002). Cronbach's alpha ranged from 0.68 to 0.93 and from 0.67 to 0.90 for HADS-A and HADS-D, respectively (Bjelland et al. 2002). In this study, a score of 8 or above in HADS-A was indicative of anxiety, and a score of 8 or above in HADS-D was indicative of depression, as this cut-off point has reached "an optimal balance between sensitivity and specificity" of the instrument (Bjelland et al. 2002; Dahl et al. 2005; Snaith 2003).

\section{- Lung Cancer Symptom Scale (LCSS) (patient completed)}

The LCSS is a disease-specific questionnaire for measuring QoL in lung cancer patients (Hollen et al. 1994). A total of nine visual analogue scales (VAS) are included in the patient-reported version, with six addressing common symptoms in lung cancer (loss of appetite, cough, breathlessness, fatigue, pain, and coughing up blood) and another three summarising patients' symptom distress, daily activities and global QoL (Hollen et al. 1994). Each VAS item is scored on a 100-mm horizontal line and the average score of the nine VAS items represents the total LCSS score (Hollen et al. 1994; Pérol et al. 2016). Higher scores reflect worse QoL (Pérol et al. 2016). Good reliability of the LCSS is reported, with internal consistency coefficient of 0.82 (Hollen et al. 1994). Validity of the LCSS was also supported by adequate content validity, construct validity and criterion-related validity (Hollen et al. 1993; 1994).

\section{Statistical analysis}

Data analysis was performed using the IBM SPSS Statistics for Windows version 22.0 (IBM Corp, Armonk, NY, USA). For all analyses in this paper, $P<0.05$ was determined as the probability level of statistical significance. Caregiver and patient demographic and clinical data, such as gender, age, employment status, treatment status, and status of anxiety and depression, etc., were summarised using descriptive statistics. For caregiver and patient-reported outcomes (CBS, CQOLC, HADS and LCSS), mean, standard deviation (SD), minimum and maximum value for both total and domain scores were calculated. Normality test with Shapiro-Wilk approach was employed to determine the use of parametric or non-parametric test, and Mann-Whiney $U$ test was adopted to explore the 
difference in HADS scores between the caregiver and patient sample, as the majority of the HADS scores in our study sample were not normally distributed.

Relationships of caregiver-reported outcomes with caregiver and patient demographic and clinical data including gender, ECOG/WHO performance status, and presence of anxiety and depression were analysed by Independent t-test or Mann-Whitney $U$ test. As the majority of the variables in either the caregiver or patient sample were not normally distributed, Spearman's correlations were used to explore the associations between caregiver-reported outcomes and caregiver and patient age. Spearman's correlation was also used to explore the interrelationships among CBS, CQOLC and caregiver HADS, as well as the associations between all caregiver and patient-reported outcomes. Correlation coefficients $(r)$ less than 0.30 indicate weak associations, an $r$ between 0.30 and 0.59 indicates moderate associations, while $r$ greater than 0.60 represent strong associations (MartínezMartín et al. 2007).

\section{RESULTS}

\section{Description of caregiver and patient characteristics and health outcomes}

Caregiver and patient demographic and clinical data are presented in Table 1, and all the caregiver and patient-reported instrument scores are listed in Table 2. More than half of the caregivers were female, aged less than 70 years old, a spouse and retired. Similarly, more than half of the patients were female and less than 70 years old and retired. Anxious subjects (HADS-A $\geq 8$ ) were identified in $46.5 \%$ of the caregiver sample and $32.6 \%$ of the patient sample and depressed subjects (HADS-D $\geq 8$ ) was $27.9 \%$ and $39.5 \%$, respectively. There was no difference between the caregiver and patient sample for either HADS-A or HADS-D scores (all at $P>0.05$ ).

\section{Relationships of caregiver-reported outcomes with caregiver and patient demographic data}

Relationships of caregiver-reported outcomes with the caregiver and patient demographic and clinical data are summarised in Table3. Generally, female caregivers had relatively higher (but nonsignificant) scores on the CBS, CQOLC and HADS than male caregivers. There was no statistically significant association between caregiver age and the majority of caregiver outcomes. Anxious and depressed caregivers experienced significantly greater burden and poorer QoL than caregivers without anxious and depressed mood, as the majority of the CBS and HADS scores were significantly higher in the anxious and depressed caregiver sample (all at $P<0.01$ or 0.05 ).

Caregivers of male patients with lung cancer (most of them were female) had relatively higher scores on most of the CBS, CQOLC and HADS variables compared to caregivers of female patients, with the CBS emotional involvement domain and CQOLC burden domain reaching statistical significance (all at $P<0.05$ ). The majority of the CBS, CQOLC and caregiver HADS scores were relatively higher (but notsignificant) in caregivers of anxious patients than those of non-anxious patients. Caregivers of depressed patients also reported higher level of burden and more impaired QoL than those of nondepressed patients, with the CBS isolation domain showing statistical significance $(P<0.01)$. Depressed mood in lung cancer patients seemed to be associated with greater emotional distress in caregivers, as caregivers of depressed patients had significantly higher HADS scores than those of non-depressed patients (all at $P<0.01$ ). 


\section{Interrelationships among caregiver-reported outcomes}

Moderately to strongly positive correlations were identified between the CBS and caregiver HADS in the majority of the variables, with the Spearman's correlation coefficients $\left(r_{\mathrm{s}}\right)$ ranging from 0.325 to 0.693 (all at $P<0.01$ or 0.05 ). Also, most of the CBS scores were positively and significantly correlated with the CQOLC total and domain scores for burden and disruptiveness, with the $r_{\mathrm{s}}$ ranging from 0.341 to 0.778 (all at $P<0.01$ or 0.05 ) (Table 4). In addition, caregiver HADS scores were closely associated with CQOLC total and domain scores for burden and disruptiveness $\left(r_{\mathrm{s}}\right.$ ranged from 0.437 to 0.825 , all at $P<0.01$ ).

\section{Associations between all caregiver-reported outcomes and all patient-reported outcomes}

Patient symptom-related QoL scores (LCSS) were moderately and positively correlated with the CBS total and domain scores for general strain, isolation and disappointment ( $r_{\mathrm{s}}$ ranged from 0.317 to 0.376 , all at $P<0.05)$, and caregiver HADS total and domain scores ( $r_{\mathrm{s}}$ ranged from 0.365 to 0.405 , all at $P<0.01$ or 0.05 ). Patient HADS scores were significantly and positively associated with caregiver HADS scores in the majority of the variables, with the $r_{\mathrm{s}}$ ranging from 0.324 to 0.623 (all at $P<0.01$ or 0.05). There were only low to moderate correlations shown between the LCSS and CQOLC scores (Table 5).

\section{DISCUSSION}

This exploratory study advances current literature on the understanding of the interrelationships among caregiver burden, emotional stress and QoL in caregivers of lung cancer patients. The study findings revealed that caregiver burden, emotional distress and QoL were closely interrelated with each other. Caregiver burden increased with increasing emotional distress and deteriorating QoL among caregivers. Caregivers with anxiety and depression suffered from greater burden and poorer QoL than those without such emotional distress. Analyses of caregiver outcomes with patient outcomes indicated that patient emotional problems, especially depression, was significantly linked with caregiver emotional distress and burden. Worse QoL in lung cancer patients was also associated with higher level of burden and more severe emotional problems in their caregivers.

CBS scores in our sample were similar to those reported in caregivers of chronic conditions such as chronic heart failure, chronic obstructive pulmonary disease, and paraplegia (Ågren et al. 2010; Blanes et al. 2007; Pinto et al. 2007). This reveals that caregiver burden of caring for lung cancer patients is comparable to that of other chronic health conditions which require long-term informal

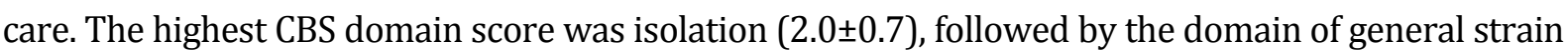
(1.9 \pm 0.6$)$, and this may be attributed to the feeling of lack of social interaction and freedom in the caregivers due to the long period of care (Ågren et al. 2010).

Anxious and depressed subjects were identified in $46.5 \%$ and $27.9 \%$ of the caregivers in our sample, and the incidence of anxiety even exceeded patients' rate (46.5 \% vs. 32.6\%). Incidence of emotional problems found in our sample was higher than that in the norm population with the prevalence for anxiety (HADS-A $\geq 8$ ) of $13.5 \%$ and depression (HADS-D $\geq 8$ ) of $10.1 \%$ (Dahl et al. 2005). This finding 
is also consistent with a previous study on caregivers of cancer patients using the same HADS cut-off level (Grov et al. 2005), which outlines the necessity of mental health support for cancer caregivers since many do not often seek for medical assistance for themselves (Girgis et al. 2013; Vanderwerker et al.2005).

QoL in our caregiver sample was better than that reported in caregivers of patients with end-stage cancer (Leow et al. 2014; Wadhwa et al, 2013). End-of-life cancer patients are usually limited in selfcare, and this can result in a great deal of care demands on their caregivers, which in turn, might place further negative impacts on caregiver QoL. However, the lung cancer patients in our sample were mostly capable of self-care (trial inclusion criteria necessitated an ECOG/WHO performance score of at least 2), and this could be one of the reasons for contributing to relatively better QoL in our caregiver sample.

Our findings showed a trend towards worse burden, emotional distress and QoL in caregivers with female gender. Female gender has been suggested as a potential predictor for caregiver distress (Matthews et al. 2003), and the explanations might be that female caregivers take more roles "inside and outside of the family" (Northouse et al. 2000, p281), and also, compared with male, female caregivers tend to be more willing to disclose their difficulties of the caregiver duty and emotional problems (Northouse et al. 2000). There was no obvious correlation between caregiver-reported outcomes and caregiver age, which is in line with previous studies on chronic conditions (Chio et al. 2005; Martínez-Martín et al. 2007). Our findings also revealed that caregivers of male lung cancer patients experienced more burden and distress than those of female patients. This is not surprising as most of the caregivers of male patients in our sample were female. Another reason might be because male patients usually "rely solely on their wives" (p281) but female patients are more likely to receive informal care from both their husbands and other family members or friends (Northouse et al. 2000).

In line with the study of Fujinami and colleagues (2015), caregiver burden was shown to be significantly associated with caregiver emotional distress and QoL, and similar results were also reported in caregivers of patients with chronic diseases (Chio et al. 2005; Martínez-Martín et al. 2007). Our findings indicated a significant impact of cancer care on the global health status of the caregivers, although causality between caregiver burden and their emotional problems and QoL impairment remains unclear. Given the close interrelationships among caregiver burden, emotional status and QoL, it seems reasonable that healthcare professionals take more efforts to relieving caregiver burden and adopt early interventions to deal with their emotional problems.

Our study showed that patient QoL was closely associated with caregiver burden and emotional status; and patient emotional problem, especially depression, was also significantly related to caregiver emotional distress. Depressed patients are often more disabled than those without depression (Martínez-Martín et al. 2007), and this could be part of the reasons for contributing to more emotional distress and burden in caregivers of depressed patients. These findings indicated a possibility that improvement of symptom management and psychological well-being in lung cancer 
patients could also create a positive impact on easing caregiver burden and emotional distress, and family-based or partner-centred interventions with specific symptom management components and emotional support could be an option offered to both patients and their caregivers. There were only low-to-moderate correlations between patient and caregiver QoL in our study, and this either can be caused by the small sample size, or it may just indicate a real weak correlation between patient and caregiver QoL. Given the conflicting evidence at present on the relationships between caregiver and cancer patient QoL (Chen et al. 2004; Litzelman et al., 2016; Sarna et al. 2006; Shahi et al. 2014; Wadhwa et al. 2013), additional studies are warranted to further investigate this issue.

This study has several limitations. The cross-sectional nature of this study made the directional analysis of the study variables impossible. The caregiver sample size was limited because of the difficulty of the caregiver recruitment in the feasibility RCT, as the symptom management intervention was not specifically designed for caregivers, and caregiver burden was also not the primary focus of the trial. The limited sample size more or less made the significance of some variables underestimated, which also made a further multivariate analysis inappropriate. The majority of the patients in our study sample were not terminally ill, which limited the generalizability of the study findings to caregivers of lung cancer patients at end-of-life. Moreover, the study findings might not be generalizable to other informal caregivers such as significant others (family members) as the majority of the caregivers in our sample were spouses or partners of the patients. Despite these limitations, the preliminary evidence identified in this exploratory study presents a close interrelationship among caregiver health outcomes, and a significant linkage between caregiver and cancer patient well-being, which emphasise the importance of treating caregivers and patients as a unit for tailored symptom management and psychosocial support.

There is a need for future studies with larger sample size to further assess the impact of patient disease-related factors (e.g. symptom severity, disease progress, and treatment duration, etc.) and caregiver personal and social factors (e.g. sexual and marital relationship with the patient, and duration of informal care, etc.) on caregiver outcomes, and to further explore the associations of caregiver burden and health status with both caregiver and lung cancer patient long-term outcomes including psychiatric and physical morbidity, and mortality. Future studies are encouraged to include a longitudinal study design with dyadic analysis to see whether outcomes between cancer patients and their caregivers are influenced over time. A predictive model with potential risk factors for caregiver burden and QoL impairment is necessary to be developed for guiding more targeted supportive service for both lung cancer patients and their caregivers.

\section{CONCLUSION}

This study contributes to further understanding of the interrelationships among caregiver burden, emotional stress and QoL in caregivers of lung cancer patients. Caregiver burden is closely associated with caregiver emotional status and QoL. High incidence of anxiety and depression identified in caregivers of lung cancer patients calls for early mental health supportive services. Caregiver burden and emotional status are positively related to patient QoL, and caregiver emotional status is also significantly associated with patient emotional conditions. Since there is minimal research focusing 
on the interventions for addressing caregiver burden in lung cancer, the close linkage between caregiver and patient health outcomes provides indications that lung cancer patients and their caregivers should be viewed as a unit in future supportive service, and family-based, or partnercentred interventions could be considered for enhancing both patients' and caregivers' well-being.

\section{Acknowledgement}

The authors would like to thank the following research staff for their contributions to the study: June Warden, Jackie Ellis, Peter Mackereth, Ann Caress, Karen Luker, Amelie Harle, Jacky Smith, Fiona Blackhall, Joanne Bayly, Loraine Morgan, Paula Maycock, Eileen Hackman, Claire Gregory and Mark Pilling. The authors are also very grateful to all the caregivers and patients for participating in this study.

\section{Funding}

This study was funded by Marie Curie Cancer Care (Ref: C16396/A14093). 


\section{REFERENCES}

Ågren, S., Evangelista, L., \& Strömberg, A. (2010). Do partners of patients with chronic heart failure experience caregiver burden?. European Journal of Cardiovascular Nursing, 9(4), 254-262.

Andrén, S., \& Elmståhl, S. (2005). Family caregivers' subjective experiences of satisfaction in dementia care: aspects of burden, subjective health and sense of coherence. Scandinavian Journal of Caring Sciences, 19(2), 157-168.

Andren, S., \& Elmståhl, S. (2008). The relationship between caregiver burden, caregivers' perceived health and their sense of coherence in caring for elders with dementia. Journal of Clinical Nursing, 17(6), 790-799.

Beesley, L. (2006). Informal Care in England. The King's Fund, London, UK.

Bjelland, I., Dahl, A. A., Haug, T. T., \& Neckelmann, D. (2002). The validity of the Hospital Anxiety and Depression Scale: an updated literature review. Journal of Psychosomatic Research, 52(2), 69-77.

Blanes, L., Carmagnani, M. I. S., \& Ferreira, L. M. (2007). Health-related quality of life of primary caregivers of persons with paraplegia. Spinal Cord, 45(6), 399-403.

Braun, M., Mikulincer, M., Rydall, A., Walsh, A., \& Rodin, G. (2007). Hidden morbidity in cancer: spouse caregivers. Journal of Clinical Oncology, 25(30), 4829-4834.

Carter, P. A. (2006). A brief behavioral sleep intervention for family caregivers of persons with cancer. Cancer Nursing, 29(2), 95-103.

Chen, M. L., Chu, L., \& Chen, H. C. (2004). Impact of cancer patients' quality of life on that of spouse caregivers. Supportive Care in Cancer, 12(7), 469-475.

Chessick, C. A., Perlick, D. A., Miklowitz, D. J., Kaczynski, R., Allen, M. H., Morris, C. D., \& Marangell, L. B. (2007). Current suicide ideation and prior suicide attempts of bipolar patients as influences on caregiver burden. Suicide and Life-Threatening Behavior, 37(4), 482-491.

Chio, A., Gauthier, A., Calvo, A., Ghiglione, P., \& Mutani, R. (2005). Caregiver burden and patients' perception of being a burden in ALS. Neurology, 64(10), 1780-1782.

Clavarino, A. M., Lowe, J. B., Carmont, S. A., \& Balanda, K. (2002). The needs of cancer patients and their families from rural and remote areas of Queensland. Australian Journal of Rural Health, 10(4), 188-195.

Dahl, A.A., Haaland, C.F., Mykletun, A., Bremnes, R., Dahl, O., Klepp, O., Wist, E. and Fosså, S.D., (2005). Study of anxiety disorder and depression in long-term survivors of testicular cancer. Journal of Clinical Oncology, 23(10), 2389-2395.

Ellis, J. (2012). The impact of lung cancer on patients and carers. Chronic Respiratory Disease, 9(1), 39-47.

Elmståhl, S., Malmberg, B., \& Annerstedt, L. (1996). Caregiver's burden of patients 3 years after stroke assessed by a novel caregiver burden scale. Archives of Physical Medicine and Rehabilitation, 77(2), 177-182.

Fujinami, R., Sun, V., Zachariah, F., Uman, G., Grant, M., \& Ferrell, B. (2015). Family caregivers' distress levels related to quality of life, burden, and preparedness. Psycho-Oncology, 24(1), 54-62.

Fox, S. W., \& Lyon, D. E. (2006). Symptom clusters and quality of life in survivors of lung cancer. Oncology Nursing Forum 33 (5), 931-936.

Girgis, A., \& Lambert, S. (2009). Caregivers of cancer survivors: the state of the field. Cancer Forum, 33:167-171.

Girgis, A., Lambert, S., Johnson, C., Waller, A., \& Currow, D. (2013). Physical, psychosocial, relationship, and economic burden of caring for people with cancer: a review. Journal of Oncology Practice, 9(4), 197-202.

Given, B., Wyatt, G., Given, C., Gift, A., Sherwood, P., DeVoss, D., \& Rahbar, M. (2004). Burden and depression among caregivers of patients with cancer at the end-of-life. Oncology Nursing Forum, 31 (6), 1105-1117.

Grov, E. K., Dahl, A. A., Moum, T., \& Fosså, S. D. (2005). Anxiety, depression, and quality of life in caregivers of patients with cancer in late palliative phase. Annals of Oncology, 16(7), 1185-1191.

Grunfeld, E., Coyle, D., Whelan, T., Clinch, J., Reyno, L., Earle, C.C., Willan, A., Viola, R., Coristine, M., Janz, T. and Glossop, R., (2004). Family caregiver burden: results of a longitudinal study of breast cancer patients and their principal caregivers. Canadian Medical Association Journal, 170(12), 1795-1801. 
Hollen, P.J., Gralla, R.J., Kris, M.G., Cox, C., Belani, C.P., Grunberg, S.M., Crawford, J. and Neidhart, J.A., (1994). Measurement of quality of life in patients with lung cancer in multicenter trials of new therapies. Psychometric assessment of the Lung Cancer Symptom Scale. Cancer, 73(8), 2087-2098.

Hollen, P. J., Gralla, R. J., Kris, M. G., \& Potanovich, L. M. (1993). Quality of life assessment in individuals with lung cancer: testing the Lung Cancer Symptom Scale (LCSS). European Journal of Cancer, 29, S51-S58.

Hooley, P. J., Butler, G., \& Howlett, J. G. (2005). The relationship of quality of life, depression, and caregiver burden in outpatients with congestive heart failure. Congestive Heart Failure, 11(6), 303-310.

Janda, M., Steginga, S., Dunn, J., Langbecker, D., Walker, D., \& Eakin, E. (2008). Unmet supportive care needs and interest in services among patients with a brain tumour and their carers. Patient Education and Counseling, 71(2), 251-258.

Kim, Y., Duberstein, P. R., Sörensen, S., \& Larson, M. R. (2005). Levels of depressive symptoms in spouses of people with lung cancer: effects of personality, social support, and caregiving burden. Psychosomatics, 46(2), 123-130.

Kim, Y., \& Given, B. A. (2008). Quality of life of family caregivers of cancer survivors. Cancer, 112(S11), 25562568.

Kim, Y., Ryn, M., Jensen, R. E., Griffin, J. M., Potosky, A., \& Rowland, J. (2015). Effects of gender and depressive symptoms on quality of life among colorectal and lung cancer patients and their family caregivers. Psycho-Oncology, 24(1), 95-105.

Kurtz, M. E., Given, C. W., Given, B. A., \& Kurtz, J. C. (1994). The interaction of age, symptoms, and survival status on physical and mental health of patients with cancer and their families. Cancer, 74(S7), 2071-2078.

Lafaye, A., De Chalvron, S., Houédé, N., Eghbali, H., \& Cousson-Gélie, F. (2013). The Caregivers Quality of Life Cancer index scale (CQoLC): an exploratory factor analysis for validation in French cancer patients' spouses. Quality of Life Research, 22(1), 119-122.

Leow, M. Q., Chan, M. F., \& Chan, S. W. (2014). Predictors of change in quality of life of family caregivers of patients near the end of life with advanced cancer. Cancer Nursing, 37(5), 391-400.

Litzelman, K., Green, P. A., \& Yabroff, K. R. (2016). Cancer and quality of life in spousal dyads: spillover in couples with and without cancer-related health problems. Supportive Care in Cancer, 24(2), 763-771.

Martínez-Martín, P., Forjaz, M.J., Frades-Payo, B., Rusinol, A.B., Fernández-García, J.M., Benito-León, J., Arillo, V.C., Barberá, M.A., Sordo, M.P. and Catalán, M.J., (2007). Caregiver burden in Parkinson's disease. Movement Disorders, 22(7), 924-931.

Matthews, B. A., Baker, F., \& Spillers, R. L. (2003). Family caregivers and indicators of cancer-related distress. Psychology, Health \& Medicine, 8(1), 46-56.

Milbury, K., Badr, H., Fossella, F., Pisters, K. M., \& Carmack, C. L. (2013). Longitudinal associations between caregiver burden and patient and spouse distress in couples coping with lung cancer. Supportive Care in Cancer, 21(9), 2371-2379.

Molassiotis, A., Lowe, M., Blackhall, F., \& Lorigan, P. (2011). A qualitative exploration of a respiratory distress symptom cluster in lung cancer: cough, breathlessness and fatigue. Lung Cancer, 71(1), 94-102.

Northouse, L. L., Mood, D., Templin, T., Mellon, S., \& George, T. (2000). Couples' patterns of adjustment to colon cancer. Social Science \& Medicine, 50(2), 271-284.

Oken, M. M., Creech, R. H., Tormey, D. C., Horton, J., Davis, T. E., Mcfadden, E. T., \& Carbone, P. P. (1982). Toxicity and response criteria of the Eastern Cooperative Oncology Group. American Journal of Clinical Oncology, 5(6), 649-656.

Ozer, Z. C., Firat, M. Z., \& Bektas, H. A. (2009). Confirmatory and exploratory factor analysis of the caregiver quality of life index-cancer with Turkish samples. Quality of Life Research, 18(7), 913-921.

Pérol, M., Ciuleanu, T.E., Arrieta, O., Prabhash, K., Syrigos, K.N., Goksel, T., Park, K., Kowalyszyn, R.D., Pikiel, J., Lewanski, C.R. and Thomas, M., (2016). Quality of life results from the phase 3 REVEL randomized clinical 
trial of ramucirumab-plus-docetaxel versus placebo-plus-docetaxel in advanced/metastatic non-small cell lung cancer patients with progression after platinum-based chemotherapy. Lung Cancer, 93, 95-103.

Perz, J., Ussher, J. M., Butow, P., \& Wain, G. (2011). Gender differences in cancer carer psychological distress: an analysis of moderators and mediators. European Journal of Cancer Care, 20(5), 610-619.

Pinto, R. A., Holanda, M. A., Medeiros, M. M., Mota, R. M., \& Pereira, E. D. (2007). Assessment of the burden of caregiving for patients with chronic obstructive pulmonary disease. Respiratory Medicine, 101(11), 24022408.

Plant, H., Moore, S., Richardson, A., Cornwall, A., Medina, J., \& Ream, E. (2011). Nurses' experience of delivering a supportive intervention for family members of patients with lung cancer. European Journal of Cancer Care, 20(4), 436-444.

Rha, S. Y., Park, Y., Song, S. K., Lee, C. E., \& Lee, J. (2015). Caregiving burden and the quality of life of family caregivers of cancer patients: the relationship and correlates. European Journal of Oncology Nursing, 19(4), 376-382.

Sarna, L., Cooley, M. E., Brown, J. K., Williams, R. D., Chernecky, C., Padilla, G., \& Danao, L. L. (2006). Quality of life and health status of dyads of women with lung cancer and family members. Oncology Nursing Forum, 33 (6), 1109-1116.

Shahi, V., Lapid, M. I., Kung, S., Atherton, P. J., Sloan, J. A., Clark, M. M., \& Rummans, T. A. (2014). Do age and quality of life of patients with cancer influence quality of life of the caregiver?. Journal of Geriatric Oncology, 5(3), 331-336.

Snaith, R. P. (2003). The hospital anxiety and depression scale. Health and Quality of Life Outcomes, 1(1), 1.

Stenberg, U., Ruland, C. M., \& Miaskowski, C. (2010). Review of the literature on the effects of caring for a patient with cancer. Psycho-Oncology, 19(10), 1013-1025.

Torre, L. A., Bray, F., Siegel, R. L., Ferlay, J., Lortet-Tieulent, J., \& Jemal, A. (2015). Global cancer statistics, 2012. CA: a cancer journal for clinicians, 65(2), 87-108.

Vanderwerker, L. C., Laff, R. E., Kadan-Lottick, N. S., McColl, S., \& Prigerson, H. G. (2005). Psychiatric disorders and mental health service use among caregivers of advanced cancer patients. Journal of Clinical Oncology, 23(28), 6899-6907.

Wadhwa, D., Burman, D., Swami, N., Rodin, G., Lo, C., \& Zimmermann, C. (2013). Quality of life and mental health in caregivers of outpatients with advanced cancer. Psycho-Oncology, 22(2), 403-410.

Weitzner, M. A., Haley, W. E., \& Chen, H. (2000). The family caregiver of the older cancer patient. Hematology/Oncology Clinics of North America, 14(1), 269-281.

Weitzner, M. A., Jacobsen, P. B., Wagner Jr, H., Friedland, J., \& Cox, C. (1999). The Caregiver Quality of Life Index-Cancer (CQOLC) scale: development and validation of an instrument to measure quality of life of the family caregiver of patients with cancer. Quality of Life Research, 8(1-2), 55-63.

Williamson, G. M., \& Shaffer, D. R. (2001). Relationship quality and potentially harmful behaviors by spousal caregivers: How we were then, how we are now. Psychology and Aging, 16(2), 217-226.

Yorke, J., Lloyd-Williams, M., Smith, J., Blackhall, F., Harle, A., Warden, J., Ellis, J., Pilling, M., Haines, J., Luker, K. and Molassiotis, A., (2015). Management of the respiratory distress symptom cluster in lung cancer: a randomised controlled feasibility trial. Supportive Care in Cancer, 23(11), 3373-3384.

Zigmond, A. S., \& Snaith, R. P. (1983). The hospital anxiety and depression scale. Acta Psychiatrica Scandinavica, 67(6), 361-370. 


\section{TABLES}

Table 1 Demographic and clinical information of study samples

\begin{tabular}{|c|c|c|}
\hline Demographic/clinical information & & Number (\%) \\
\hline \multicolumn{3}{|l|}{ Caregiver sample $(\mathrm{N}=43)$} \\
\hline \multirow{4}{*}{ Caregiver's age (year) } & $<70$ & $28(65.1 \%)$ \\
\hline & $\geq 70$ & $12(27.9 \%)$ \\
\hline & Not recorded & $3(7.0 \%)$ \\
\hline & Mean (SD) & $61.7(12.4)$ \\
\hline \multirow[t]{2}{*}{ Caregiver's gender } & Female & $28(65.1 \%)$ \\
\hline & Male & $15(34.9 \%)$ \\
\hline \multirow[t]{6}{*}{ Relationship with patient } & Wife & $18(41.9 \%)$ \\
\hline & Husband & $14(32.6 \%)$ \\
\hline & Daughter & $5(11.6 \%)$ \\
\hline & Friend & $3(7.0 \%)$ \\
\hline & Partner & $2(4.7 \%)$ \\
\hline & Sister & $1(2.3 \%)$ \\
\hline \multirow[t]{2}{*}{ Employment status } & Retired & $24(55.8 \%)$ \\
\hline & Not retired & $19(44.2 \%)$ \\
\hline \multirow[t]{3}{*}{ Presence of anxiety } & Yes (HADS-A $\geq 8$ ) & $20(46.5 \%)$ \\
\hline & No (HADS-A <8) & $21(48.8 \%)$ \\
\hline & No recorded & $2(4.7 \%)$ \\
\hline \multirow[t]{3}{*}{ Presence of depression } & Yes (HADS-D $\geq 8$ ) & $12(27.9 \%)$ \\
\hline & No (HADS-D <8) & $29(67.4 \%)$ \\
\hline & Not recorded & $2(4.7 \%)$ \\
\hline \multicolumn{3}{|l|}{ Patient sample $(\mathrm{N}=43)$} \\
\hline \multirow[t]{3}{*}{ Patient's age (year) } & $<70$ & $24(55.8 \%)$ \\
\hline & $\geq 70$ & $19(44.2 \%)$ \\
\hline & Mean (SD) & $67.1(10.6)$ \\
\hline \multirow[t]{2}{*}{ Patient's gender } & Female & $22(51.2 \%)$ \\
\hline & Male & $21(48.8 \%)$ \\
\hline \multirow[t]{6}{*}{ Employment } & Retired & $35(81.4 \%)$ \\
\hline & In paid employment & $4(9.3 \%)$ \\
\hline & Housewife & $1(2.3 \%)$ \\
\hline & Long-term sickness & $1(2.3 \%)$ \\
\hline & Never worked & $1(2.3 \%)$ \\
\hline & Not recorded & $1(2.3 \%)$ \\
\hline \multirow[t]{3}{*}{ ECOG/WHO performance status } & Grade $1^{\mathrm{A}}$ & $20(46.5 \%)$ \\
\hline & Grade $2^{\mathrm{B}}$ & $15(34.9 \%)$ \\
\hline & Not recorded & $8(18.6 \%)$ \\
\hline \multirow[t]{3}{*}{ Patient treatment status } & Absence of further active antineoplastic therapy & $6(14.0 \%)$ \\
\hline & Post-curative treatment & $17(39.5 \%)$ \\
\hline & Follow-up palliative cancer care & $20(46.5 \%)$ \\
\hline \multirow[t]{3}{*}{ Presence of anxiety } & Yes (HADS-Anxiety $\geq 8$ ) & $14(32.6 \%)$ \\
\hline & No (HADS-Anxiety <8) & $27(62.8 \%)$ \\
\hline & No recorded & $2(4.7 \%)$ \\
\hline \multirow[t]{3}{*}{ Presence of depression } & Yes (HADS-Depression $\geq 8$ ) & $17(39.5 \%)$ \\
\hline & No (HADS-Depression <8) & $25(58.1 \%)$ \\
\hline & Not recorded & $1(2.3 \%)$ \\
\hline
\end{tabular}

HADS: Hospital Anxiety and Depression Scale

A: ECOG/WHO performance status Grade 1: "Restricted in physically strenuous activity but ambulatory and able to carry out work of a light or sedentary nature" (Oken et al. 1982, p654); B: ECOG/WHO performance status Grade 2: "Ambulatory and capable of all self-care but unable to carry out any work activities" (Oken et al. 1982, p654). 
Table 2 Summary of caregiver and patient-reported outcomes

\begin{tabular}{lccccc}
\hline & N & Mean & SD & Minimum & Maximum \\
\hline CBS (Caregiver) & & & & & \\
\hline CBS total & 43 & 1.8 & 0.5 & 1.1 & 3.1 \\
CBS general strain & 43 & 1.9 & 0.6 & 1.0 & 3.6 \\
CBS isolation & 43 & 2.0 & 0.7 & 1.0 & 3.7 \\
CBS disappointment & 43 & 1.8 & 0.6 & 1.0 & 3.0 \\
CBS emotional involvement & 43 & 1.4 & 0.6 & 1.0 & 3.3 \\
CBS environment & 43 & 1.6 & 0.6 & 1.0 & 3.3 \\
\hline CQOLC (Caregiver) & & & & \\
\hline CQOLC total & 26 & 43.2 & 15.2 & 21.0 & 83.0 \\
CQOLC burden & 38 & 17.8 & 9.2 & 5.0 & 38.0 \\
CQOLC disruptiveness & 40 & 4.7 & 4.9 & 0.0 & 24.0 \\
CQOLC positive adaptation & 36 & 12.1 & 5.6 & 4.0 & 23.0 \\
CQOLC financial concerns & 40 & 1.6 & 2.5 & 0.0 & 9.0 \\
\hline HADS (Caregiver) & & & & & \\
\hline HADS total & 41 & 13.0 & 7.6 & 1.0 & 28.0 \\
HADS anxiety & 41 & 8.0 & 3.9 & 1.0 & 15.0 \\
HADS depression & 41 & 5.1 & 4.2 & 0.0 & 9.0 \\
\hline HADS (Patient) & & & & & \\
\hline HADS total & 41 & 13.8 & 7.6 & 3.0 & 32.0 \\
HADS anxiety & 41 & 7.5 & 4.5 & 0.0 & 18.0 \\
HADS depression & 42 & 6.4 & 4.3 & 0.0 & 16.0 \\
\hline LCSS (Patient) & 43 & 39.2 & 15.3 & 4.6 & 72.7 \\
\hline CBS: Cargive & & & & \\
\hline
\end{tabular}

CBS: Caregiver Burden Scale; CQOLC: The Caregivers Quality of Life Index-Cancer; HADS: Hospital Anxiety and Depression Scale; LCSS: Lung Cancer Symptom Scale 
Table 3 Relationships of caregiver outcomes with caregiver and patient demographic data

\begin{tabular}{|c|c|c|c|c|c|c|c|c|c|c|c|c|c|c|c|c|c|c|c|c|c|}
\hline \multirow[t]{2}{*}{ Caregiver outcomes } & \multicolumn{3}{|c|}{ Caregiver gender } & \multicolumn{3}{|c|}{ Anxious caregiver } & \multicolumn{3}{|c|}{ Depressed caregiver } & \multicolumn{3}{|c|}{ Patient gender } & \multicolumn{3}{|c|}{ Patient ECOG/WHO status } & \multicolumn{3}{|c|}{ Anxious Patient } & \multicolumn{3}{|c|}{ Depressed Patient } \\
\hline & Female & Male & $P$ value & Yes & No & $P$ value & Yes & No & $P$ value & Female & Male & $P$ value & Grade $1^{A}$ & Grade2 ${ }^{\mathrm{B}}$ & Pvalue & Yes & No & $P$ value & Yes & No & $P$ value \\
\hline \multicolumn{22}{|l|}{ CBS } \\
\hline Total & 1.8 & 1.7 & $0.216^{\mathrm{U}}$ & 2.1 & 1.5 & $\mathbf{0 . 0 0 0}^{\mathrm{T}}$ & 2.2 & 1.6 & $\mathbf{0 . 0 0 1}^{\mathrm{U}}$ & 1.7 & 1.9 & $0.230^{\mathrm{T}}$ & 1.6 & 1.7 & $0.388^{\mathrm{T}}$ & 1.9 & 1.7 & $0.355^{\mathrm{T}}$ & 1.9 & 1.6 & $0.055^{\mathrm{T}}$ \\
\hline General strain & 2.0 & 1.8 & $0.357^{\mathrm{T}}$ & 2.3 & 1.6 & $\mathbf{0 . 0 0 0} 0^{\mathrm{T}}$ & 2.4 & 1.7 & $0.001 \mathrm{U}$ & 1.8 & 2.0 & $0.415^{\mathrm{T}}$ & 1.7 & 1.9 & $0.355^{\mathrm{T}}$ & 2.0 & 1.8 & $0.254^{\mathrm{T}}$ & 2.1 & 1.7 & $0.145^{\mathrm{T}}$ \\
\hline Isolation & 2.1 & 1.8 & $0.352^{\mathrm{U}}$ & 2.2 & 1.7 & $0.059^{\mathrm{U}}$ & 2.4 & 1.8 & $0.029^{u}$ & 1.8 & 2.1 & $0.242^{\mathrm{U}}$ & 1.8 & 2.0 & $0.314^{\mathrm{U}}$ & 1.9 & 2.0 & $0.734^{\mathrm{U}}$ & 2.3 & 1.7 & $0.007^{\mathrm{U}}$ \\
\hline Disappointment & 1.9 & 1.6 & $0.151^{\mathrm{U}}$ & 2.1 & 1.5 & $\mathbf{0 . 0 0 0}^{\mathrm{T}}$ & 2.3 & 1.7 & $0.002^{\mathrm{U}}$ & 1.7 & 2.0 & $0.109^{\mathrm{T}}$ & 1.6 & 1.7 & $0.486^{\mathrm{T}}$ & 1.9 & 1.7 & $0.347^{U}$ & 1.9 & 1.7 & $0.198^{\mathrm{T}}$ \\
\hline Emotional involvement & 1.5 & 1.4 & $0.150^{\mathrm{U}}$ & 1.7 & 1.2 & $0.026^{U}$ & 1.6 & 1.4 & $0.524^{U}$ & 1.3 & 1.5 & $0.049^{u}$ & 1.5 & 1.3 & $0.330^{\mathrm{U}}$ & 1.6 & 1.3 & $0.924^{U}$ & 1.6 & 1.3 & $0.554^{\mathrm{U}}$ \\
\hline Environment & 1.5 & 1.6 & $0.628^{\mathrm{U}}$ & 1.8 & 1.3 & $\mathbf{0 . 0 0 1}{ }^{\mathrm{U}}$ & 1.8 & 1.5 & $0.088^{\mathrm{U}}$ & 1.6 & 1.5 & $0.566^{\mathrm{U}}$ & 1.4 & 1.6 & $0.314^{\mathrm{U}}$ & 1.7 & 1.5 & $0.523^{\mathrm{U}}$ & 1.7 & 1.5 & $0.444^{\mathrm{U}}$ \\
\hline \multicolumn{22}{|l|}{ CQOLC } \\
\hline Total & 46.2 & 39.1 & $0.248^{\mathrm{T}}$ & 53.9 & 35.0 & $\mathbf{0 . 0 0 0}^{\mathrm{T}}$ & 56.3 & 40.2 & $0.004^{U}$ & 39.8 & 49.6 & $0.123^{\mathrm{T}}$ & 38.2 & 44.3 & $0.312^{\mathrm{T}}$ & 46.2 & 41.6 & $0.472^{\mathrm{T}}$ & 48.8 & 39.1 & $0.148^{\mathrm{T}}$ \\
\hline Burden & 19.2 & 15.1 & $0.199^{\mathrm{T}}$ & 25.4 & 12.4 & $\mathbf{0 . 0 0 0}^{\mathrm{T}}$ & 24.8 & 16.3 & $\mathbf{0 . 0 2 0}{ }^{\mathrm{T}}$ & 14.7 & 20.8 & $0.038^{\mathrm{T}}$ & 15.5 & 19.9 & $0.187^{\mathrm{T}}$ & 18.9 & 16.6 & $0.261^{\mathrm{U}}$ & 20.1 & 15.4 & $0.156^{\mathrm{U}}$ \\
\hline Disruptiveness & 5.7 & 2.9 & $0.123^{\mathrm{U}}$ & 7.1 & 2.8 & $0.002^{\mathrm{U}}$ & 8.5 & 3.1 & $\mathbf{0 . 0 0 4}$ & 4.4 & 5.1 & $0.592^{\mathrm{U}}$ & 3.4 & 5.3 & $0.381^{\mathrm{U}}$ & 4.1 & 4.7 & $0.938^{\mathrm{U}}$ & 5.9 & 3.5 & $0.234^{U}$ \\
\hline Positive adaptation & 12.1 & 12.0 & $0.967^{\mathrm{T}}$ & 11.5 & 12.6 & $0.560^{\mathrm{T}}$ & 14.0 & 11.3 & $0.210^{\mathrm{T}}$ & 12.6 & 11.5 & $0.553^{\mathrm{T}}$ & 12.0 & 11.5 & $0.795^{\mathrm{T}}$ & 12.5 & 12.0 & $0.829^{\mathrm{T}}$ & 12.3 & 12.0 & $0.897^{\mathrm{T}}$ \\
\hline Financial concerns & 1.7 & 1.5 & $0.820^{\mathrm{U}}$ & 2.1 & 0.9 & $0.154^{\mathrm{U}}$ & 2.5 & 1.1 & $0.356^{\mathrm{U}}$ & 1.2 & 2.1 & $0.369^{\mathrm{U}}$ & 1.0 & 1.5 & $0.682^{\mathrm{U}}$ & 1.8 & 1.6 & $0.210^{\mathrm{U}}$ & 2.6 & 1.0 & $0.196^{U}$ \\
\hline \multicolumn{22}{|l|}{ Caregiver HADS } \\
\hline Total & 13.6 & 11.8 & $0.422^{\mathrm{U}}$ & NA & NA & NA & NA & NA & NA & 12.2 & 13.9 & $0.449^{\mathrm{U}}$ & 10.9 & 14.4 & $0.154^{\mathrm{T}}$ & 15.1 & 11.5 & $0.118^{U}$ & 17.4 & 9.5 & $\mathbf{0 . 0 0 0}^{\mathrm{T}}$ \\
\hline Anxiety & 8.3 & 7.3 & $0.438^{\mathrm{T}}$ & NA & NA & NA & NA & NA & NA & 7.3 & 8.6 & $0.304^{\mathrm{T}}$ & 7.0 & 8.8 & $0.142^{\mathrm{T}}$ & 9.4 & 7.0 & $0.067^{\mathrm{T}}$ & 10.1 & 6.3 & $\mathbf{0 . 0 0 1}{ }^{\mathrm{T}}$ \\
\hline Depression & 5.4 & 4.5 & $0.559 \mathrm{U}$ & NA & NA & NA & NA & NA & NA & 4.9 & 5.3 & $0.555^{\mathrm{U}}$ & 3.9 & 5.6 & $0.573^{\mathrm{U}}$ & 5.7 & 4.5 & $0.361^{\mathrm{U}}$ & 7.3 & 3.2 & $0.002^{U}$ \\
\hline
\end{tabular}

Scores are presented as mean.

CBS: Caregiver Burden Scale; CQOLC: The Caregivers Quality of Life Index-Cancer; HADS: Hospital Anxiety and Depression Scale; LCSS: Lung Cancer Symptom Scale

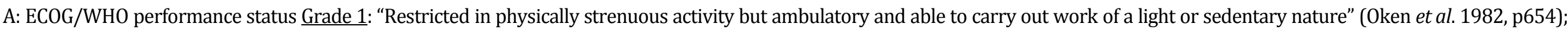

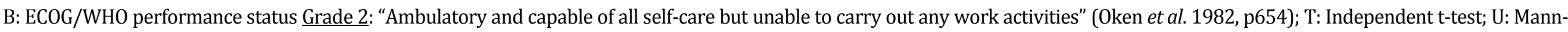

Whitney U test 
Table 4 Associations among CBS and CQoLC and caregiver HADS

\begin{tabular}{|c|c|c|c|c|c|c|c|c|}
\hline \multirow[t]{2}{*}{ CBS scores } & \multicolumn{5}{|c|}{ CQOLC scores } & \multicolumn{3}{|c|}{ Caregiver HADS scores } \\
\hline & Total & Burden & Disruptiveness & $\begin{array}{c}\text { Positive } \\
\text { adaptation }\end{array}$ & $\begin{array}{l}\text { Financial } \\
\text { concerns }\end{array}$ & Total & Anxiety & Depression \\
\hline Total & $0.778^{a}$ & $0.498^{a}$ & $0.728^{a}$ & 0.088 & 0.220 & $0.685^{a}$ & $0.693^{a}$ & $0.590^{\mathrm{a}}$ \\
\hline General strain & $0.746^{\mathrm{a}}$ & $0.460^{\mathrm{a}}$ & $0.716^{a}$ & 0.123 & 0.171 & $0.634^{\mathrm{a}}$ & $0.682^{\mathrm{a}}$ & $0.497^{a}$ \\
\hline Isolation & $0.684^{a}$ & $0.341^{b}$ & $0.498^{a}$ & 0.219 & -0.017 & $0.502^{a}$ & $0.443^{a}$ & $0.501^{\mathrm{a}}$ \\
\hline Disappointment & $0.565^{\mathrm{a}}$ & $0.514^{a}$ & $0.557^{a}$ & -0.037 & 0.296 & $0.590^{\mathrm{a}}$ & $0.575^{a}$ & $0.503^{a}$ \\
\hline Emotional involvement & 0.130 & 0.217 & $0.350^{b}$ & -0.018 & 0.260 & $0.325^{b}$ & $0.390^{\mathrm{b}}$ & 0.270 \\
\hline Environment & 0.348 & 0.280 & $0.399^{b}$ & -0.049 & 0.138 & $0.484^{a}$ & $0.531^{\mathrm{a}}$ & $0.408^{a}$ \\
\hline
\end{tabular}

CBS: Caregiver Burden Scale; CQOLC: The Caregivers Quality of Life Index-Cancer; HADS: Hospital Anxiety and Depression Scale

a: significant at 0.01 ; b: significant at 0.05

Table 5 Associations between all caregiver measures and all patient measures

\begin{tabular}{|c|c|c|c|c|}
\hline \multirow[t]{3}{*}{ Caregiver outcomes } & \multicolumn{4}{|c|}{ Patient outcomes } \\
\hline & \multicolumn{3}{|c|}{ Patient HADS score } & \multirow{2}{*}{$\begin{array}{c}\text { LCSS score } \\
\text { LCSS total }\end{array}$} \\
\hline & HADS total & HADS anxiety & HADS depression & \\
\hline \multicolumn{5}{|l|}{ CBS score } \\
\hline CBS total & 0.217 & 0.044 & 0.266 & $0.374^{b}$ \\
\hline CBS general strain & 0.167 & 0.029 & 0.202 & $0.334^{b}$ \\
\hline CBS isolation & 0.286 & 0.006 & $0.472^{a}$ & $0.317^{b}$ \\
\hline CBS disappointment & 0.132 & 0.047 & 0.151 & $0.376^{b}$ \\
\hline CBS emotional involvement & 0.064 & 0.089 & 0.038 & 0.128 \\
\hline CBS environment & 0.270 & 0.164 & 0.211 & 0.193 \\
\hline \multicolumn{5}{|l|}{ CQOLC score } \\
\hline CQoLC total & 0.297 & 0.043 & 0.317 & 0.201 \\
\hline CQoLC burden & 0.289 & 0.217 & 0.240 & 0.291 \\
\hline CQoLC disruptiveness & 0.122 & -0.048 & 0.216 & $0.314^{b}$ \\
\hline CQoLC positive adaptation & 0.107 & 0.017 & 0.158 & -0.181 \\
\hline CQoLC financial concerns & 0.259 & 0.271 & 0.097 & $0.363^{b}$ \\
\hline \multicolumn{5}{|l|}{ Caregiver HADS score } \\
\hline HADS total & $0.547^{a}$ & 0.294 & $0.623^{a}$ & $0.404^{a}$ \\
\hline HADS anxiety & $0.539^{a}$ & $0.324^{b}$ & $0.592^{a}$ & $0.405^{a}$ \\
\hline HADS depression & 0.519 & 0.243 & $0.605^{\mathrm{a}}$ & $0.365^{b}$ \\
\hline
\end{tabular}

CBS: Caregiver Burden Scale; CQOLC: The Caregivers Quality of Life Index-Cancer; HADS: Hospital Anxiety and Depression Scale; LCSS: Lung Cancer Symptom Scale

a: significant at 0.01 ; b: significant at 0.05 